\title{
Evaluation of kyphosis in Mazandaran University of Science and Technology students and its relation to psychological factors
}

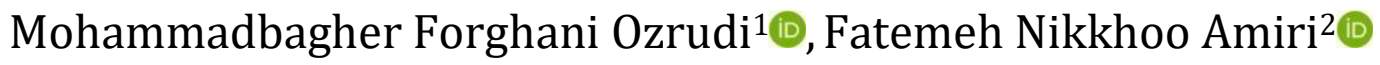 \\ ${ }^{1}$ Physical Education Teacher, Education Office, Babol, Iran. ${ }^{2}$ Department of Corrective Exercise, Physical Education and Sports \\ Sciences, University of Tehran, Tehran, Iran.
}

\begin{abstract}
Nowadays a large and growing field of health psychology, researchers do point out, any logical reason for the establishment of a psychosomatic patient. This study examined the Evaluation of Kyphosis in Mazandaran University of Science and Technology students and its relation to psychological factors. The method used in this research is descriptive correlation method is implemented. Population study of boys and girls were 56 (31 boys and 25 girls) and who had kyphosis has voluntarily participated in this study. The spinal mouse was used to measure the kyphosis angle and for its assessment of the patient's spine-concept, depression and anxiety are better examples of MMPI-2RF questionnaire (Reconstruction form of Minnesota Multidimensional Personality Questionnaire) ( $\alpha=0.84)$, test Beck Depression Inventory $(\alpha=0.85)$, and test anxiety or Spielberger's $(\alpha=0.87)$, were used. The results showed that using the Pearson correlation coefficient between self-concept ( $\mathrm{r}=0.52$; $\mathrm{P}=0.13)$, depression ( $\mathrm{r}=0.54 ; \mathrm{P}=0.41)$, and anxiety $(\mathrm{r}=0.34 ; \mathrm{P}=0.28)$, and no significant correlation with kyphosis $(\mathrm{p}<0.05)$. The results showed that the student alone kyphosis indicative of anxiety, depression and self-concept is not sick but creates kyphosis is related to other social and environmental factor. The results showed that in patients with kyphosis alone is not an indication of mental disorders but should be considered in the treatment of patients with these abnormalities to psychological factors.
\end{abstract}

Keywords. Kyphosis, male and female students, psychological factors.

\section{Introduction}

Quality and how the human body is of particular importance in human life. Because positive and negative changes and changes caused by other conditions that affect human (Honari, 1993). During the middle decades of the twentieth century, the concept of the relationship between body and mind formed the new achievements that extensive research was followed. During the decades become a phenomenon Freud resorted to physical manifestations of mental states are represented as reactions. Sadock \& et al. (2014) believed that special unconscious conflicts with mental-body disorders are related. Nowadays a large and growing field of health psychology, researchers do point out, any logical reason for the establishment of a psychosomatic patient (Mahavi et al., 2019). Spine plays different roles in the body; one of its most important roles is to support the chest. Chest due to the internal organs, especially the heart needs a lot of support, so spine plays a major role as support (Mahavi et al., 2019). Like other parts of the body part is affected by mental and also mental is influenced by the body. Research findings have shown that spinal special relationship with some mental states and the effect of factors such as depression and mental illness, isolation and loss of its proper shape, such as with kyphosis, Posture Deformity and scoliosis (Dekel et al., 1996). Kyphosis of the spine symptoms that seem to be associated with these states and phenomena. This phenomenon can be observed in non-human aspects of psychological phenomena mentioned.

On the other hand, psychological aspects to it gradually and therefore invisible, physical condition and other aspects affecting or affected them. Several

$\triangle$ M. F. Ozrudi, e-mail: mohammadbagher.forghani@gmail.com

Received: January 06, 2021 - Accepted: March 23, 2021 - Published: March 30, 2021

To Cite: Ozrudi, M. F., Amiri, F. N. (2021). Evaluation of kyphosis in Mazandaran University of Science and Technology students and its relation to psychological factors. Turk J Kinesiol, 7(1), 39-43. DOI: 10.31459/turkjkin.855111 
investigations have been carried deformity of the spine and psychological factors. Including that of Norris et al. (1999) and Bumgratner \& Sucer (1990) showed that there is a relationship between body condition and psychological factors (Norris et al., 1992; Bumgratner \& Sucer, 1990). A researcher believes, there is bodily and mental indicator for agitation. Perception agitations are mental indicator from agitation in which leads to fear of negative effect on society, fear from failure and decreasing selfesteem (Khanjani et al., 2014). Noonan et al. (1997) also demonstrated features of psychological effects on patients with spinal deformities. In contrast, Balzini et al. (2003) who studied clinical treatment of people with spinal posture deformity have demonstrated that there is no deformity of the spine condition.

Asghari (2006) and Samadi et al. (2009) also had been done on the correlation between psychosocial factors and failed to achieve an average kyphosis. At other universities in Tehran. A clinical term of anxiety happens in behavioral, physical, and cognitive matters. Since every emotional state has a psychosocial component and a physical component, thus anxiety requires some kinds of physical symptoms (Bagherian-Sararoudi et al., 2019). Another concept of anxiety symptom is concerning the physical situation or fear of having some future of the diseases (Dadsetan, 2016). Mental illness and depression can affect the body in some way, someone who is experiencing depression and inferiority complex due to mental disorders (lack of confidence and confusion of mind) so that their feeble sense on how this situation bodies in various states of being negatively affected. Emotions and circumstances affect muscle movement and how the body works (Karimi, 1996).

Some researchers such as Norris et al. (1999) and Bumgratner \& Sucer (1990) have shown that anxiety and depression are associated with abnormalities of the body. A study found that over 90 percent of patients with impaired disfigure the body of a period of major depressive disorder in their life experience, about 70 percent had an anxiety disorder, and 30 percent had been suffering Piloctic disorder (Sanatkaran, 1999). Mosburger \& Egel (2000) to assess personality disorders in patients with spinal disorders was conducted; it was found that all of them have anxious and depressive personality disorders. Balzini et al. (2003) in a clinical practice on people who have postural abnormalities. Results showed that those who are bent more height, more depression, and lower motivation in compression with smaller bent stature. The findings show that depression can lead to the body being disobedient, stiff neck and back pain, but we cannot exclude that depression may play role in rigidity, postural scoliosis, because physical activity is reduced in depressed patients and it may cause spinal muscles are weak and elongation.

Asghari \& Imanzadeh (2009) found that between athletes and non-athletes kyphosis with depression and anxiety, there is no significant relationship, but no significant relationship was found between kyphosis with depression.

According to what has been explained above and the lack of relevant research subjects in the world and Iran, the present study examined the association between kyphosis, and anxiety, depression, and patient imaginary Mazandaran University of Science and Technology.

\section{Methods}

Type of descriptive study was conducted on the correlation method. The population of boys and girls in the test were 56 ( 31 boys and 25 girls) and they had kyphosis and they voluntarily participated in this study. All participants gave written consent to their participation before the study. The study was conducted following Helsinki Declaration. This article has been done with the moral code 14512 on 23 December 2020, which was approved by the research committee of Mazandaran University of Science and Technology.

\section{Research Tools}

Mouse spinal cord: This device is composed of a mouse and an antenna that is connected to the monitor. Digital mouse have rollers, with these rollers the spine curvature and angle of them will display towards the monitor. To assess the physical condition of which he or she is asked to stand straight and then sign the seventh cervical vertebrae $\left(\mathrm{C}_{7}\right)$ and next degree of kyphosis on the page share, according to the program have previously installed the mouse as quiet and careful in keeping the spine is stretched to the outer nut. By Dragging the mouse on the spine of the seventh cervical vertebra to the sacrum and then record the nuts spinal back arch bending mode and body opening is done, then the image arcs and curvature of the spine kyphosis person will display. To find the number of kyphosis subjects, the device, and program set up to analyze the data from the first nut to the twelfth chest kyphosis person ( $\mathrm{T}_{1}$ to $\mathrm{T}_{12}$ ) show up. These amounts were recorded for each 
patient as the degree of kyphosis. The inter-group and intra-group reliability of this instrument to measure the overall arcs backbone is shown in a standing position (Mannion et al, 2004). Beck Depression is applicable to various classes and strata of society (Becker et al., 1987). The test reflects the depth of depression among depressed and nondepressed value detection is clean. This test has 13 questions. The test-retest reliability was examined directly and indirectly retest correlations range of 53 to 89 is obtained. Beck validity in two separate studies, 0.65 and 0.69 is shown (Godarzi, 2003). Also, in Iran, the Beck Depression test reliability and validity have been reported. To assess reliability in terms of Cronbach's alpha internal reliability coefficient of Beck Depression Inventory and classification method based on a questionnaire, the questions were odd and even. Cronbach's alpha coefficient of the questionnaire was $84 \%(\mathrm{~N}=260)$ represents the internal consistency of the questionnaire. The correlation coefficient obtained from the classified $70 \%(\mathrm{~N}=260)$ was $(p<0.01)$, which shows the reliability of the questionnaire. Godarzi, form 13-item Beck Depression Inventory reported that Iran can run and not culturally dependent (Godarzi, 2003). The present study aimed to determine the reliability of the questionnaire, a preliminary study was conducted, and Cronbach's correlation coefficient $(\alpha=0.87)$ was determined. Spielberger's test anxiety or burgers for a person or group of persons is applicable. This test has no time limit for its completion and test time is usually six minutes. This questionnaire is a 20-question multiple-choice (Spielberger's et al., 1983). To determine the validity and content validity method was used to determine the reliability of the questionnaire, a preliminary study was conducted, and Cronbach's correlation coefficient $(\alpha=0.89)$ were determined. To assess the patient's self-concept subject's adjusted MMPI-2RF questionnaire were used. This test consists of 71 questions about the validity of the short form that has been shown to culture (Shamounian et al., 2013). In a preliminary investigation the reliability of this test in the present study using Cronbach's alpha coefficient of 0.85 , respectively.

One hundred ninety-eight students at Mazandaran University of Science and Technology voluntarily completed the informed consent form and become familiar with how to research the written form attached to the consent form, the backbone of the examination was conducted by the mouse, the patients who had the kyphosis degrees of more than 40 were 56 people, the number of correlations is appropriate. First, each of these individuals was asked the Beck Depression Inventory and the Trait Anxiety Inventory, or MMPI-2RF, Spielberger's and finally adjusted to complete the questionnaire. Questionnaires were completed by each subject on average lasted 25 minutes. After scoring each question for each sample Pearson correlation to assess the association of each variable with the amount of kyphosis were psychic. All statistical calculations at the significant level of 0.05 . were performed using the software SPSS 19.

\section{Results}

To investigate the relationship between the kyphosis and psychological factors, Pearson correlation analysis was used. The results are presented in two tables in compressed form. In Table 1, individual characteristics, degree of kyphosis, and psychological factors samples, respectively, are presented. The correlation between the degree of kyphosis with depression, anxiety, and self-concept are reported in Table 2.

As the Table 1 is shown, the mean kyphosis of the subjects was $48.03 \pm 5.2$.

Table 1
Individual characteristics and degree of kyphosis (Mean \pm
SD).
\begin{tabular}{lcc}
\hline Variables & Girl & Boy \\
\hline Age (year) & $21.13 \pm 2.3$ & $22.34 \pm 2.8$ \\
Height (cm) & $174.4 \pm 5.6$ & $178.1 \pm 5.4$ \\
Weight (kg) & $71.31 \pm 4.7$ & $74.41 \pm 4.6$ \\
Kyphosis (degree) & $48.04 \pm 5.4$ & $48.09 \pm 5.1$ \\
\hline
\end{tabular}

The results in Table 2 indicate that the rate of depression in subjects using the Beck Depression Inventory $12.74 \pm 5.61$ (Mean \pm SD) and also their anxiety was measured using the trait anxiety Spielberger's $43.04 \pm 7.16$. Analysis of data obtained from a modified MMPI-2RF questionnaire also showed that self-concept subjects $33.24 \pm 5.3$. Also, the kyphosis samples and all the psychological factors evaluated in this study there was no significant association $(p<0.05)$. The mean of Pearson correlation coefficient between girls and boys and the significance level kyphosis associated with any psychological factors are self-concept $(\mathrm{r}=$ $0.56 ; p=0.15)$, depression $(\mathrm{r}=0.54 ; \mathrm{P}=0.39)$, and anxiety $(\mathrm{r}=-0.36 ; p=0.32)$. 


\section{Table 2}

Correlation coefficients between psychological factors and degree of kyphosis according to gender.

\begin{tabular}{llccc}
\hline Gender & Variables & Mean \pm SD & $r$ & $p$ \\
\hline Girl & Depression and kyphosis & $12.74 \pm 5.61$ & 0.50 & 0.43 \\
& Anxiety and kyphosis & $43.04 \pm 7.16$ & -0.32 & 0.34 \\
& Self-concept and kyphosis & $33.24 \pm 5.3$ & 0.51 & 0.13 \\
Boy & Depression and kyphosis & $12.49 \pm 5.47$ & 0.54 & 0.39 \\
& Anxiety and kyphosis & $41.08 \pm 6.76$ & -0.36 & 0.32 \\
& Self-concept and kyphosis & $32.41 \pm 4.2$ & 0.56 & 0.15 \\
\hline
\end{tabular}

\section{Discussion}

The present study seeks to examine the relationship between spinal deformity (kyphosis), and psychological factors such as depression, anxiety, and self-concept are sick. The results indicated that the demographic characteristics (age, height, weight) and kyphosis relationship exist, but the amount varies depending on the severity of the kyphosis. The results are consistent with Rajabi's results (2013). The results of this study showed that none of the psychological factors (depression, anxiety, and selfconcept) were significantly associated with kyphosis $(p<0.05)$.

The findings of Balzini et al. (2003) that the clinical behavior of patients with abnormalities on physical conditions studied is compatible. The findings with the results of the Asghari (2006), kyphosis, and the lack of a significant association between depression and anxiety are consistent with reported students. But Rezazadeh's research that examines the extent of body condition and depression disorders in male patients in Tehran Shahid Chamran hospital was inconsistent (Narimani, 2020), the correlation high coefficient of between depression and body condition showed abnormalities (Asghari, 2006). According to the results of Asghari \& Imanzadeh, there is no significant relationship between kyphosis with depression and anxiety in athletes and non-athletes, but the relationship between kyphosis is consistent with both inconsistent with the depression outcomes (Asghari \& Imanzadeh, 2009).

The lack of consistency between the findings of the survey results can be found in the number of samples, type of hospital patients with the severe congenital condition, and those who have been hospitalized. The results regarding the relationship between selfconcept and kyphosis result Hansson \& Jensen (2004) is confirmed, but the results of Samadi et al. (2008) are inconsistent with the lack of consistency may be due to differences in samples of the studies knew they were being studied in the research elderly female patients, but in this study, the sample comprised students with an average age of about 23 years.

\section{Conclusion}

The results showed that in patients with kyphosis alone is not an indication of mental disorders but should be considered in the treatment of patients with these abnormalities to psychological factors. Postural abnormalities could adversely affect body perception, particularly in young people. If they don't detect and treat, may affect physiological function. Musculoskeletal disorders not only affect physical health and organ function, but they are effective on Psychological factors. So, it can be concluded that ontime identification of a sign will have a great impact on community member's physical and mental health.

\section{Conflict of Interest}

Authors declared no conflict of interest.

\section{References}

Asghari, A. (2006). Determine the degree of association between depression and anxiety disorders, spinal conditions in student-athletes and non-athletes selected University of Tehran. Master's thesis, Islamic Azad University, Iran.

Asghari, A., Imanzadeh, M. (2009). Relationship between kyphosis and depression anxiety in athlete and nonathlete male students in selected universities of Tehran. World Applied Sciences Journal, 7(10), 13111316.

Bagherian-Sararoudi, R., Peyman, A., Askari, K., Molavi, H., Sajadinajad, M., \& Zargar, F. (2019). A comparison of psychological adjustment and type D personality between ulcerative colitis patients and normal in 
Isfahan city. Thoughts and Behavior in Clinical Psychology, 13(47), 17-26.

Balzini, L., Vannucchi, L., Benvenuti, F., Benucci, M., Monni, M., Cappozzo, A., \& Stanhope, S. J. (2003). Clinical characteristics of flexed posture in elderly women. Journal of the American Geriatrics Society, 51(10), 14191426.

Becker, R. E., Heimberg, R. G., \& Bellack, A. S. (1987). Social skills training treatment for depression. Allyn \& Bacon.

Bumgratner, A., \& Sucer, N. (1990). Physical activity and posture idiopathic. TSH and Thyroid Harmonies Research, 34(2), 213-215.

Dadsetan, P. (2016). Excerpts from the largest systems of evolutionary psychology. Organization for the Study and Compilation of University Humanities Books (Samat), Center for Research and Development of Humanities.

Dekel, Y., Tenenbaum, G., \& Kudar, K. (1996). An exploatory syudy on the relationship between postural deformities and body-image and self-esteam in adolescents: The mediating role of physical activity. J Sport Psychology, 2(27), 183-196.

Ghorbani, N. (2000). Physiological consequences of failure and emotional disclosure in therapy. Doctoral thesis, Tarbiat Modarres University, Iran.

Godarzi, M. A. (2003). Validity and reliability of beck depression inventory. Journal of Humanities and Social Sciences, 36, 26-39.

Hansson, T., \& Jensen I. (2004). Sickness absence due to back and neck disorders. Scand J Public Health, 32(63), 109-151.

Honari, H. (1993). Review and understanding of musculoskeletal abnormalities male athlete of students across the country. Master thesis, Tarbiat Modares University, Iran.

Karimi, Y. (1996). Psychology of personality theory and research. Tehran: Tehran Publishers.

Khanjani, M., Bararzadeh, M., \& Forghani Ozrudi, M. B. (2014). Relaxation practice influence on mood competitive agitation in female karate fighter. International Journal of Sport Studies, 4(1), 67-71.

Letafatkar, A., Daneshmandi, H., Hdadnjad, M., \& Abdolvahabi, Z. (2019). Advanced corrective exercises to practice. $5^{\text {th }}$ Edition, Tehran: Publisher Avaye Entazar, Iran.

Mahavi, S.M., Etemaddar, N., Esmaeili, M., Gholampoor, Y. (2019). The relationship between personality traits and coping strategies in the alexithymia prediction of chronic obstructive pulmonary patients referred to
Valiasr Hospital in Fasa. Journal of Fasa University of Medical Sciences, 9(3), 1646-1656.

Mannion, A. F., Knecht, K., Balaban, G., Dvorak, G., \& Grob, D. (2004). A new skin-surface device for measuring the curvature and global and segmental ranges of motion of the spine: Reliability of measurements and comparison with data reviewed from the literature. Eur Spine J, 13, 122-136.

Mosburger, H., Egel, S. (2000). Determine of pain exercise: perceived competence, trait anxiety, trait depression and moderate effects. Pers Individ Dif, 12, 1261-1266.

Narimani, M. (2020). Personality assessment. Tabriz, Iran: Ardabil, Shaykh Safi Publications.

Noonan, K. J., Dolan, L. A., Jacobson, W. C., \& Weinstein, S. L. (1997). Long-term psychosocial characteristics of patients treated for idiopathic scoliosis. Journal of Pediatric Orthopedics, 17(6), 712-717.

Norris, R., Carroll, D., \& Cochrane, R. (1992). The effects of physical activity and exercise training on psychological stress and well-being in an adolescent population. Journal of Psychosomatic Research, 36(1), 55-65.

Rajabi, R. (2013). The relationship between the degrees of thoracic kyphosis with some anthropometric factors in Iranian society. Contemporary research in the Journal of Sport Management, 2(4), 111-125.

Rezazadeh, A. (1995). Evaluation of the relationship between postural disorders and depression in male patients in Shahid Dr. Chamran Hospital. Master's Thesis, Iran University of Medical Sciences, Iran.

Sadock, B. J., Sadock, V. A., Pedro Ruiz, S. (2014). Kaplan and Sadock's synopsis of psychiatry: behavioral sciences/clinical psychiatry, $11^{\text {th }}$ edition. Philadelphia, United States: LWW,

Samadi, H., Rajabi, R., \& Shahi, Y. (2008). Investigating the relationship between the degree of kyphosis and psychological factors in male students of Tehran University. The Quarterly Journal of Fundamentals of Mental Health, 10(37), 55-61.

Sanatkaran, A. (1999). Effect of relaxation training on anxiety, competitive state and performance of selected women's basketball club. Master's thesis, Islamic Azad University, Iran.

Shamounian, E., Forghani Ozrudi, M. B., \& Tojari, F. (2013). The survey of psychological characteristics (personality and cognitive) of elite cyclists of Iran. Journal of Sport Psychology, 1(1), 69-80.

Spielberger, C. D., Gorsuch, R. L., \& Lushene, R. (1983). State-trait anxiety inventory STAI (Form Y). Redwood City: Mind Garden. 